Article

\title{
Optimizing Energy Efficiency in Operating Built Environment Assets through Building Information Modeling: A Case Study
}

\author{
Ioan Petri ${ }^{1, *}$ (D), Sylvain Kubicki ${ }^{2}$ (D), Yacine Rezgui ${ }^{1}$, Annie Guerriero ${ }^{2}$ and Haijiang Li $^{1}$ \\ 1 BRE Institute in Sustainable Engineering, School of Engineering, Cardiff University, Cardiff CF243AA, UK; \\ rezguiy@cardiff.ac.uk (Y.R.); LiH@cardiff.ac.uk (H.L.) \\ 2 Luxembourg Institute of Science and Technology (LIST), L-4362 Esch-sur-Alzette, Luxembourg, \\ Luxembourg; sylvain.kubicki@list.lu (S.K.); annie.guerriero@list.lu (A.G.) \\ * Correspondence: petrii@cardiff.ac.uk; Tel.: +44-(0)29-2087-9150
}

Received: 5 April 2017; Accepted: 2 August 2017; Published: 8 August 2017

\begin{abstract}
Reducing carbon emissions and addressing environmental policies in the construction domain has been intensively explored with solutions ranging from energy efficiency techniques with building informatics to user behavior modelling and monitoring. Such strategies have managed to improve current practices in managing buildings, however decarbonizing the built environment and reducing the energy performance gap remains a complex undertaking that requires more comprehensive and sustainable solutions. In this context, building information modelling (BIM), can help the sustainability agenda as the digitalization of product and process information provides a unique opportunity to optimize energy-efficiency-related decisions across the entire lifecycle and supply chain. BIM is foreseen as a means to waste and emissions reduction, performance gap minimization, in-use energy enhancements, and total lifecycle assessment. It also targets the whole supply chain related to design, construction, as well as management and use of facilities, at the different qualifications levels (including blue-collar workers). In this paper, we present how building information modelling can be utilized to address energy efficiency in buildings in the operation phase, greatly contributing to achieving carbon emissions targets. In this paper, we provide two main contributions: (i) we present a BIM-oriented methodology for supporting building energy optimization, based on which we identify few training directions with regards to BIM, and (ii) we provide an application use case as identified in the European research project "Sporte2" to demonstrate the advantages of BIM in energy efficiency with respect to several energy metrics.
\end{abstract}

Keywords: building information modeling; energy optimization; buildings; operation phase; training

\section{Introduction}

Global warming has drastically increased the pressure to reduce energy use in buildings. In the $\mathrm{EU}$, energy for the building sector represents more than $40 \%$ of Europe's energy and $\mathrm{CO}_{2}$ emissions. The European Commission has defined a clear 2020 target to reduce by $20 \%$ the energy consumption and the $\mathrm{CO}_{2}$ emissions and increase by $20 \%$ the share of renewable energies. These objectives have been translated into stringent regulations and policies at the European and national levels. For instance, the recast of the Energy Performance of Buildings Directive (2010/31/EU) imposes stringent energy efficiency requirements for new and retrofitted buildings [1].

The global construction market is forecast to grow by over $70 \%$ by 2025 [2]. Several countries have already set-up the target to achieve sizeable objectives, such as the United Kingdom (UK) construction agenda: (a) 33\% reduction in both the initial cost of construction and the whole life cost of assets; (b) $50 \%$ reduction in the overall time from inception to completion for new build and refurbished 
assets; (c) 50\% reduction in greenhouse gas emissions in the built environment; (d) $50 \%$ reduction in the trade gap between total exports and total imports for construction products and materials $[3,4]$.

The construction industry hence presents a major opportunity to reduce energy demand, improve process efficiency and reduce carbon emissions; it is also traditionally highly fragmented and often portrayed as involving a culture of "adversarial relationships", "risk avoidance", exacerbated by a "linear workflow", which often leads to low efficiency, delays and construction waste. The process of designing, re-purposing, constructing and operating a building or facility involves not only the traditional disciplines, but also many new professions in areas such as energy and the environment [5].

In this context, building information modelling (BIM) can facilitate more effective energy modelling and multi-disciplinary collaborations with a total lifecycle and supply chain integration perspective. Building information modelling provides a digital representation of the building process, facilitating the exchange and interoperability of information in digital format; this modelling can greatly contribute to energy reduction. BIM has a number of socio-technological advantages not only at the technological level, but also the process level, and can complement the way that architectural design artefacts are created, but also can profoundly change the collaborative process associated with the act of building. As the construction industry is facing increased pressure from regulations calling for significant gains in energy efficiency, increased economic pressure and competition, and a dramatic evolution of working culture and practices, BIM can represent a game-changing factor that would support the transition to more energy and cost-efficient practices [6-9].

BIM and information and communication technologies (ICT) can play this game-changing role, by enabling faster and more reliable design of decision-making and construction follow-up. Building information modelling (BIM), at first, has proven to provide for enhancement of design support (through 3D visualization, physical simulation, upstream assessment of design options) and construction planning and monitoring (construction phasing and continuous monitoring). Such advanced support from digital tools is likely to allow for significant improvements in the quality and energy performance of buildings, as well as time and cost-savings to preserve competiveness of European businesses. During these different phases (as presented in Figure 1), the building information model has to be enriched by large data, notably related to building components, or simulated and/or sensed usages in order to support the energy analyses and simulations.

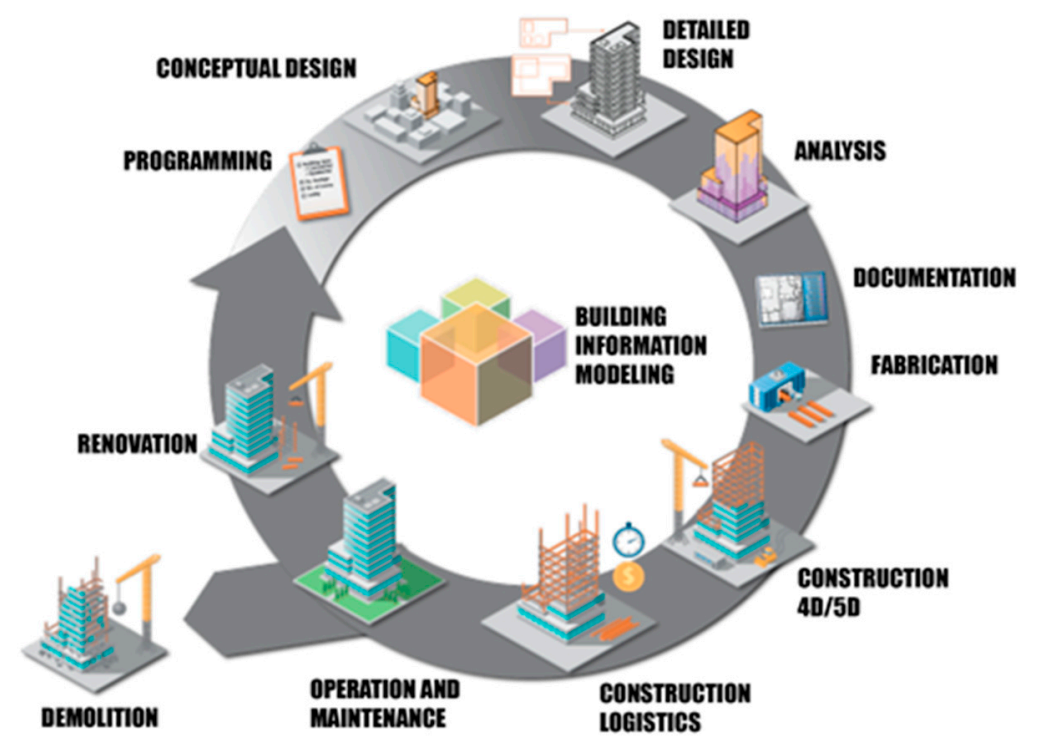

Figure 1. Building information modelling (BIM) uses across building lifecycle (copyright Lloyd's Register).

Consequently, our paper focuses on the operation phase and on understanding and utilizing BIM as a toolset to optimize energy. We evaluate how a BIM-based approach including using accurate energy 
monitoring, real-time decision support systems, and actuators and identification of consumption patterns, can impact the overall energy profile of a building. We evaluate BIM use for energy efficiency: (a) the reliance on a semantic approach (i.e., BIM, real-time data analysis, behaviour modelling, etc.); (b) enhanced supervision of energy flows and use in buildings; and (c) new partnerships between energy managers, energy distributors, energy equipment suppliers, and technology (including smart software tools).

We focus on demonstrating the benefits of building information modelling in maximizing energy efficiency and sustainable outcomes. We use BIM as a means to monitor building performance, employ various BIM tools during the operation and maintenance phase of a project, with a view to reducing the actual energy consumption in buildings. In validating our work, we use an application use case related to energy efficiency in buildings realized as part of the EU FP7 Sporte2 project based on which we demonstrate how BIM can reduce energy consumption and improve the overall building management process. We also briefly identify training strategies for improving skills and competencies for construction actors in the field of BIM.

The remainder of the paper is as follows: in Section 2 we present several studies and projects in the field of energy efficiency and BIM. In Section 3 we present BIM from a wider perspective with regards to building lifecycle and applications for energy efficiency. The application use case is presented in Section 4 , followed by an evaluation part in Section 5 . We provide a few discussion paragraphs on BIM's importance for energy in Section 6 and conclude our work in Section 7.

\section{Related Work and Background}

There are several research attempts in the field of building information modelling and energy efficiency trying to determine a methodology for utilizing BIM for reducing energy consumption and emissions in buildings.

Building information modelling in construction projects can support collaboration between employers, designers, suppliers and facilities managers through a range of design and construction tasks [10]. BIM has also been validated in studies [11-13] as an efficacious instrument for addressing (a) project failure caused by lack of effective project team integration across supply chains (b) the emergence of challenging new forms of procurement incl. design-build-operate contracts [14] and (c) decreasing the whole life cost of a building through the adoption of BIM in facilities management [15]. BIM also facilitates information collected and stored in a BIM-compliant database which often could be beneficial for a variety of practices, such as energy management, maintenance and repair, and space management [16].

On the research project side, there are several projects exploring novel pathways in exploiting BIM and associated training programs. The BIM4VET project [17] aims at developing a BIM competency framework and associated platform providing a repository of BIM training and recommendations for training modules. The aim of the project is to collect structured and focused feedback from a selection of BIM experts (expert panel) about BIM actor qualifications, practices, and to conduct BIM maturity assessments.

The field of energy efficiency research previously addressed the use of building information models to enable the fastest and simplest energy-related simulations during design. However, in their research, Wilkins et al. [18] state that "in the energy domain, an 'architectural view' is often transformed into a "thermal view'" (i.e., the building energy model), which causes various uncertainties regarding datasets. Ladenhauf et al. [19] undertook a systematic analysis of the relationships between BIM-based sustainability analysis software and the LEED (Leadership in Energy and Environmental Design) certification process is proposed. The authors concluded on the quickness of the BIM approach, but also mentioned that no one-to-one relationship exists so far. Schlueter et al. [20], embedded a simplified estimation of energy and exergy within traditional BIM design tools in order to provide more integrated view of buildings during early design stages. Salman et al. [21] propose an algorithm aiming at automatically creating simple building models for energy analysis purposes based on complex 
BIM IFC (industry foundation classes, the industry standard BIM data model) models, rather than doing it manually. It allowed the fastest and easiest simulation in early design, and was an alternative to proprietary CAD (computer aided design) tool formats. Addressing information workflows from design authoring to energy simulation, Cemesova et al. [22] extend the IFC schema with energy entities, allowing both descriptive and behavioural data to be stored in the same place. Finally, when considering larger scale energy systems (i.e., several buildings within a district), multi-agent simulations supported by the semantic interoperability of energy systems is a new trend to be considered [23].

The previous paragraph shows that significant research efforts focus on BIM-based assessments of building energy performance at earlier stages of building projects. Only a few papers report on research using BIM for energy efficient building operation. Costa et al. [24] consider BIM as a structure for visualizing measurements and building performance datasets. In Wong and Zhou [25], the authors review a number of studies addressing "environmental sustainability over building life cycles through green BIM" and identify that BIM used in operation and maintenance (OM) should provide efficiency, improve the quality of service to customers, reduce emergencies in OM, improve safety, and reduce resource waste. Gokce et al. [26] develop a continuous assessment process by combining the data from different sources and phases in a single data repository centred on a building's BIM spaces. However, Reeven et al. [27] highlight that a limitation in using BIM (associated with the building energy model (BEM)) for monitoring the building performance in operation is its "inability to simulate building performance under realistic conditions". Indeed, these authors mention that "inaccurate input related to occupant behavior and building operation is a common and substantial source of error in building performance simulations under realistic conditions". This drawback can be managed in certain BEM modelling tools.

There are also several European initiatives trying to reduce energy consumption in building by using a BIM based approach. The PERFORMER project [28] seeks to reduce the gap between predicted and actual energy consumption in public buildings and to extract from use cases/case studies evidence-based indicators of the role of BIM in energy efficiency. The KnoholEM project [29] demonstrates the use of a semantic (BIM-based) approach to optimize energy consumption in public buildings. The STREAMER project [30] relates to energy-efficient buildings with cases of mixed-use healthcare districts that aim to reduce the energy use and carbon emission of new and retrofitted buildings in healthcare districts. The QUANTUM project [31] aims to develop and demonstrate pragmatic services and appropriate tools with high replication potential supporting quality management (QM) for building performance in the design, construction, commissioning and operation phases as a mean to close the gap between predicted and actual energy performance in European buildings. The SUCCESS project [32] aims to improve the efficiency and reduce negative impacts of the construction supply chain by exploring and testing reliable and innovative solutions. HOLISTEEC [33] is a project that aims at providing the European AEC/FM (architecture, engineering, construction and facility management) industry with a comprehensive design approach taking into account the whole building life-cycle and the influence of the neighbourhoods, with the objective of making a decisive contribution to build environment energy efficiency improvement. The AIDA project [34], on the other hand, investigates the means to reduce energy consumption and carbon emissions employing BIM instruments for energy efficiency.

\section{BIM for Energy Efficiency in Buildings}

We estimate that the implementation of BIM for energy efficiency will provide energy savings through the combination of accurate energy monitoring, real-time decision support systems, and actuators and identification of consumption patterns. Moreover, (a) the reliance on a semantic approach (i.e., BIM, real-time data analysis, behaviour modelling, etc.); (b) enhanced supervision of energy flows and use in buildings; and (c) new partnerships between energy managers, energy distributors, energy equipment suppliers, and technology (including smart software tools), will inform the optimal management on the evolution of energy use in buildings, and result in quantifiable energy consumption reduction. It will provide an analytic operating capacity, KPI (key performance indicator) control, 
annual consumption forecast progress, reports and personalized alerts. A smart distribution of the (reduced) building energy consumption will imply economic savings that will be commensurate with the targeted energy reduction. Although according to some thermal regulations the energy consumption of a building is expected to not exceed a given limit, the real energy performance is usually lower. One means to reduce the gap between prediction and reality is to improve the entire process, from the early design phase to the operation phase $[8,9]$. Practitioners who use BIM during the design phase, the construction phase or the maintenance phase will contribute to improving the quality of the building's performance. A benchmark of European BIM-related projects would provide some examples of the expected efficiency we can get in construction or refurbishment projects.

Whilst often portrayed as solely a digital model, BIM is a construction process that enables the development of construction information in a coordinated and structured fashion. This "single point of the truth" provides reliable information and provides the capacity for software tools to interrogate and illustrate the developing schemes. This capacity to review and revise developing proposals in the context of integrated data has benefits from the project outset, where a more effective brief can be developed with the client and more iterative reviews/evolutions of this can be undertaken. These benefits then continue into the design phase, where appropriate use of BIM software allows rapid design prototyping and trialling of multiple options ("optioneering"), especially useful in an energy efficiency context around the impact of orientation, building layout and surface, including volume ratio of heat/cooling losses. Although often used as a construction process, BIM has a high potential impact on energy efficiency that continues beyond the client brief and concept design stages of design and construction. BIM also has a role in the delivery of energy efficiency on site through the correct delivery of information to those undertaking the construction and procurement. It is envisaged that this will increase in the future, with the uptake of wearable technologies linked to the BIM dataset providing greater accessibility and verification of the physical construction work [35,36]. Early projects utilising BIM have reported reductions in construction programme, defects, material wastage and incorrect material or component installation (UK's large contractor alone, Mott MacDonald, estimated these efficiencies at 30\%) [37]. Regarding energy efficiency, improvements relate to how BIM helps to close the "performance gap"; i.e., the difference between the designed performance of the building and the energy performance delivered by the completed construction. This gap depends not solely on construction quality as one other recognised reason is the variation between "perfect" design models and "imperfect" construction, especially in relation to the building envelope and the building's services [20,22]. In both instances, BIM enables those undertaking the construction to access and validate the current, exact requirements quickly and efficiently. Lastly, BIM has very significant potential for the operation and management (facilities management) of the building once in use. Here, the provision of accurate, reliable and accessible BIM data to those tasked with operating the building has the potential to transform the efficiency by which the building is run, realising very significant savings against current levels of operation. Related studies $[29,30]$ have demonstrated that the paralleling of BIM data against live projects can be used to generate $15-20 \%+$ energy savings through the automation of controls and live sensors/actuators. Furthermore, even without a move to full automation, notable energy savings are demonstrable where building managers have access to, and the tools to quickly and easily utilise, the detailed designs of the building, enabling more accurate "tuning" to suit conditions and occupational requirements [38,39].

An appropriately coordinated implementation of BIM which incorporates and recognises the key factors of energy efficiency around design, construction and operation therefore has extremely significant potential to drive energy efficiency through improved brief setting, more integrated and optimized design solutions, better specification and site delivery, and the more efficient operation of the building in use. In this paper, we specifically address the operation phase and employ a BIM based optimization scenario to emphasize the advantages of BIM in energy efficiency. 


\section{BIM-based Energy Efficiency Optimization Methodology}

The methodology we have adopted is presented in Figure 2 and relies on three main steps.

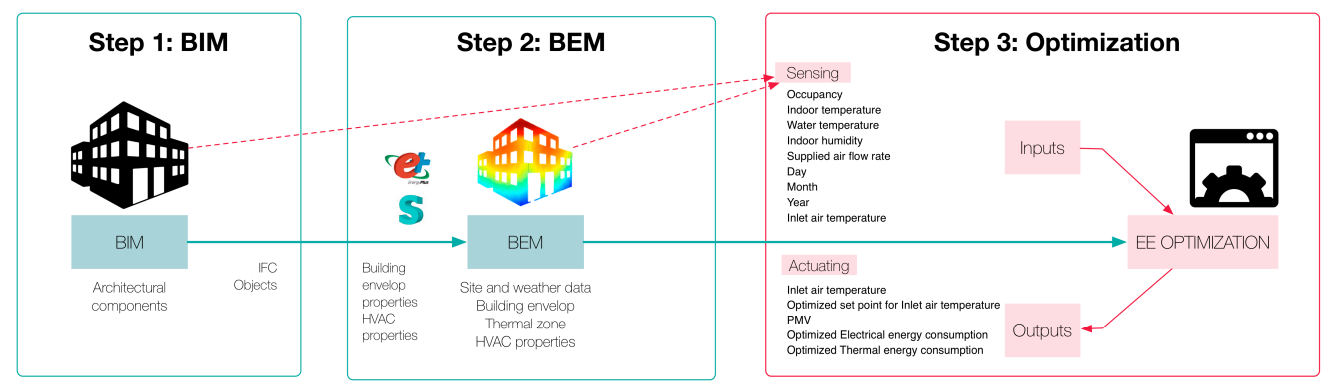

Figure 2. Optimization process based on BIM and building energy model (BEM).

\subsection{Optimization Process Based on BIM}

Step 1. The architectural BIM is the starting point in the process. Depending on the availability of a BIM model for a given building, it should be required either to use-and potentially transform-IFC BIM data, or to generate it. The authors assume that in most cases, newly-built buildings are documented with as-built BIM models (either in proprietary file formats, e.g., Revit, Archicad etc., or in IFC format). In the case of existing buildings, for which renovation is undertaken, or simply when new technical systems are installed such as heating, ventilation and air conditioning (HVAC), a BIM model should be developed. In this case, detailed modelling is not necessarily required, as the optimization process described in this paper does not rely on a very accurate description of all building objects. Rather, building properties useful to contextualize sensed data, like the classification of space usage, expected occupancy of areas, operating of openings or automated shading devices are required.

Step 2. The building energy model (BEM) comprises additional information required to run simulations. EnergyPlus [40] is an energy analysis and thermal load simulation tool that allows building performance simulations such as lighting/day-lighting, heating, ventilation and air conditioning (HVAC), service water heating, and on-site energy generation. In our optimization process, based on the BIM description associated with envelope and systems properties of a building, EnergyPlus calculated the heating and cooling loads necessary to maintain thermal control setpoints, conditions throughout a secondary HVAC system and coil loads, and the energy consumption of primary plant equipment.

Step 3. The optimization itself consists in a computational processing of input-sensed data to define the best setting of inlet air temperature, optimizing both electrical energy and thermal energy consumption, while maintaining an acceptable comfort level for users (PMV). Sensing provides input data to the optimization algorithm. BIM and building energy modelling (BEM) enable us to make sense of data by contextualizing these datasets on the basis of semantic data describing built facilities and their equipment.

\subsection{Optimization}

As an optimization algorithm, we use NSGA-II, a non-domination asynchronous sequel genetic algorithm [41]. The parallel NSGA-II inherits the original NSGA-II's population topology, search strategy and basic sketch. In the initialization phase, the genetic algorithm's population size and generation number is set, and the NSGA-II begins with a population of randomly selected individual solutions. For each individual solution, the NSGA-II submits the optimization tasks and collects the fitness values for the individual solutions. In the optimization model, we use a model name, design variable name, and variable lower and upper limit. If the design variable is a discrete variable, an array of all the candidate values of the variable is needed. The HVAC energy consumption consists of two components-thermal energy and electricity consumption - therefore the energy consumption function can be described as follows: $\mathrm{E}=\mathrm{E}_{\mathrm{t}}+\mathrm{E}_{\mathrm{e}}$, where, $\mathrm{E}_{\mathrm{t}}$ and $\mathrm{E}_{\mathrm{e}}$ represent thermal energy consumption and 
electricity consumption, respectively. E represents the total energy consumed by the building facility over the monitored period. Predicted mean vote (PMV) is used as a constraint for the optimization model and the acceptable comfort zone is defined as $-1<$ PMV $<+1$ in this scenario. The input parameters and output results are presented in Table 1 below.

Table 1. BIM optimization input and output.

\begin{tabular}{|c|c|c|c|}
\hline \multicolumn{3}{|c|}{ Inputs \& Outputs (Optimised Results) } & Unit \\
\hline $\begin{array}{l}\text { Optimisation } \\
\text { Inputs }\end{array}$ & $\begin{array}{l}\text { Parameters used for ANN } \\
\text { executable (serving as a cost } \\
\text { function for optimisation) }\end{array}$ & $\begin{array}{c}\text { Occupancy } \\
\text { Indoor Temperature } \\
\text { Water Temperature } \\
\text { Indoor Humidity } \\
\text { Supplied air flow rate } \\
\text { Day } \\
\text { Month } \\
\text { Year } \\
\text { Inlet air temperature }\end{array}$ & $\begin{array}{c}- \\
\text { deg. C } \\
\text { deg. C } \\
\% \\
\mathrm{Kg} / \mathrm{s} \\
- \\
- \\
- \\
\text { deg. C }\end{array}$ \\
\hline & $\begin{array}{l}\text { Variable to be optimised } \\
\text { (Design Variable) }\end{array}$ & Inlet air temperature & deg. C \\
\hline $\begin{array}{l}\text { Optimisation } \\
\text { outputs }\end{array}$ & $\begin{array}{c}\text { Optimised design variable } \\
\text { Constraint } \\
\text { Objective }\end{array}$ & $\begin{array}{c}\text { Optimised set point for Inlet air temperature } \\
\text { PMV } \\
\text { Optimised electrical energy consumption } \\
\text { Optimised thermal energy consumption }\end{array}$ & $\begin{array}{l}\operatorname{deg} \cdot \mathrm{C} \\
- \\
\mathrm{kW} \cdot \mathrm{h} \\
\mathrm{kW} \cdot \mathrm{h}\end{array}$ \\
\hline
\end{tabular}

Thus, we evaluate the impact of our BIM optimization solution from the perspective of how much energy can the pilot (FIDIA) save over a period when employing a BIM optimization approach.

\subsection{Artificial Neuronal Network}

We have trained our artificial neuronal network (ANN) with simulated data generated from the EnergyPlus model. The simulation program was run for one year. The dataset was generated from the simulation program every $15 \mathrm{~min}$. The simulation produced several data which were directly linked to each subsystem to provide a highly accurate simulation. The outputs of the ANN were chosen as thermal energy consumption, electrical energy consumption, and PMV index value. The selected environmental parameters either directly or indirectly affect each of the outputs. For instance, energy consumption is affected by the number of occupants, water temperature, relative humidity, supplied flow rate, and is also time dependent. Similarly, the thermal comfort level is also affected from these parameters, which were measured with PMV [42].

We use a calibrated simulation model to generate a large amount of data sets to train the corresponding ANN prediction engine. The trained ANN was then calibrated in real case and used as a cost function in an optimization program to help to achieve the energy saving target.

Several ANN models have been tested to find the best configuration on both the Visual Studio platform and MATLAB. For the C++ -based fast ANN (FANN) models we used: (i) standard backpropagation, where the weights are updated after each training pattern and (ii) advanced batch training, not the learning rate (default training algorithm). For the MATLAB-based ANN models we used: (i) conjugate gradient backpropagation with Powell-Beale restarts and (ii) gradient descent backpropagation. During the training process $80 \%$ of the data sets were randomly selected and used. The rest of the data sets were utilised for the testing stage. The datasets used in this process were selected from the facility scheduled opening hours.

For the performance testing of the training process, the following topology was utilized for all the selected learning functions: number of input $=9$, number of output $=3$, number of hidden layer $=2$, number of neurons for hidden layers $=(7,10)$, transfer function for hidden layers and output layer $=($ tangent sigmoid tangent sigmoid logarithmic sigmoid $)$, maximum number of epoch $=1000$, error rate $=0.001$, learning rate $=0.01$, and momentum coefficient $=0.8$. The parameters of the topology were selected after several empirical test results then utilized for the best performance of the comparison. 
During the empirical testing stage, several combinations of the parameter set values were tested for each of the ANN models, such as the different number of process elements, transfer function, learning rate, momentum coefficient and error rate. The error rate is one of the fundamental termination conditions for ANN, and it was selected as three digits for this use case/scenario to predict the outputs more precisely.

\subsection{Modelling}

In our evaluation cases, we compared the BIM optimization, as identified in Section 4, with traditional optimization techniques as existing in the pilot. A traditional optimization technique refers to a number of operations that pilot personnel are adopting for reducing energy consumption. All these operations are manually applied (i.e., switching off the boiler, the air fans, the lighting system, etc.) and have no automated implementation or consistent decision-making processes. A BIM optimization, on the other hand, is based on a number of BIM techniques and is related to a set of input parameters and generates optimized values according to which set-points within the building are automatically adjusted. Such BIM techniques help identifying correlations between spaces, facilities, and outdoor-indoor space connections, where modifying parameters (such as openings) in the BIM is easily reflected in the BEM and can therefore enable the running of new simulation scenarios faster. In order to provide a better comparison base for our experiments we have included an additional predicted trend for the variables that we monitored. The predicted mechanism was ensured by employing an artificial neural network (ANN) which works independently (see Section 4.3).

Values of the reported variables were recorded at intervals of $15 \mathrm{~min}$ for a period of 42 days. We consider a set $R:\left\{r_{1}, r_{2}, r_{3}, \ldots, r_{\mathrm{n}}\right\}$, where $r_{\mathrm{i}}$ represents a generic value recorded at every $15 \mathrm{~min}$ for thermal energy consumption (TEC), electrical energy consumption (EEC) and PMV. We have used two different methodologies for representing the results:

- Interval records: $r_{\mathrm{i}}$ identifies the distribution of the reported metrics as recorded every at $15 \mathrm{~min}$ intervals (Experiment 1),

- $\quad$ Total Per Day Records: total $=\sum_{j=1}^{m} r_{j}$ (Experiment 2 and Experiment 3).

\section{Application}

In this section, we provide a building application case for the operation and maintenance phase and demonstrate the impact that BIM has on reducing energy consumption within a pilot building. We deploy BIM optimization in a pilot site and record the results for a monitored period of 42 days. In order to undertake these experiments and provide a comparison base, we used one of the SportE (SportE2 is a research project co-financed by the European Commission in FP7 under the domain of Information Communication Technologies and Energy Efficient Buildings. In this project, we develop energy efficient products and services dedicated to the needs and unique characteristics of sport facilities, www.sporte2.eu) pilots called FIDIA (http:/ / www.asfidia.it), a public sport building facility, located in Rome, Italy. The objective of this BIM application case is to apply accurate energy monitoring, real-time decision support systems actuators and identification of consumption patterns that can impact the overall energy profile of the FIDIA pilot. In order to undertake this BIM optimization, we used Simergy [43], a building energy modeling (BEM) tool that facilitates the creation of a digitalized BIM model of the FIDIA pilot and also to interface with the EnergyPlus [44] software based on which we deployed our simulations.

\subsection{FIDIA Pilot}

The building we used in the pilot study has wooden external walls of $9 \mathrm{~cm}$ and a wooden external roof of $9 \mathrm{~cm}$. The floor is made of concrete. The windows are single glass with a thermal transmittance of $5.7 \mathrm{~W} / \mathrm{m}^{2} / \mathrm{K}$ and a solar gain of 0.7 . 
The geometry of the building is composed of a gable roof with $\mathrm{H}_{\min }=3 \mathrm{~m}$ and $\mathrm{H}_{\max }=6 \mathrm{~m}$ with window surfaces of about $70 \mathrm{~m}^{2}$. In addition, the building pilot is structured as follows:

- Pool (indoor)—size: $25 \mathrm{~m} \times 16 \mathrm{~m}$, depth: $1.60 \mathrm{~m}$ to $2.10 \mathrm{~m}$, Capacity: $760 \mathrm{~m}^{3}$

- Learning Pool (indoor)—size: $16 \mathrm{~m} \times 4 \mathrm{~m}$, depth: $1 \mathrm{~m}$, Capacity: $64 \mathrm{~m}^{3}$

- Gym (indoor) provided of electric equipment (electric bicycles, etc.)

- $\quad$ Fitness room (indoor)—size: $18 \mathrm{~m} \times 9 \mathrm{~m} \times 3 \mathrm{~m}$, Volume: $486 \mathrm{~m}^{3}$

- Volleyball court (indoor)—size: $40 \mathrm{~m} \times 28 \mathrm{~m} \times 8 \mathrm{~m}$, Volume: $8960 \mathrm{~m}^{3}$

- Tennis/Five-a-side courts (outdoor, with changing rooms)—size: $30 \mathrm{~m} \times 20 \mathrm{~m}$

The sports facility is equipped with sensors and actuators for the monitoring, control and optimization of the facility. The building has a metering capability to determine consumption of electricity, gas, biomass, water and thermal energy. This data can be accessed through a specialist interface and recorded for analysis. The sub-metering of thermal and electrical consumption within grouped zones (gym/fitness and swimming pool) is also provided along with "comfort" monitoring by functional area: gym, fitness room and swimming pool). In these areas, the predicted mean vote (PMV) index-which measures the average response of a group of people to a thermal sensation scale, such as hot, warm to cool, and cold-is one of the most widely recognised thermal comfort models, and is measured as a function of the activity performed within a particular part of the building. The occupancy is also monitored in the gym, fitness room and around the swimming pool area. The structure of the facility does not allow the direct measurement of the total value of occupancy for the pilot, so the occupancy of the whole facility is provided as sum of number of people who entered/exited the building over a particular time interval.

\subsection{Energy Efficiency Validation}

In this section, we evaluate the impact of BIM when used for conducting energy optimization planning. We measure how much energy can be saved over time on one of the Sporte2 project's pilots called FIDIA. We have recorded the "real energy consumption" as identified in the FIDIA pilot over a period of 42 days, and $24 \mathrm{~h}$ respectively and compared with the results obtained when running the optimization with the BIM optimization methodology in the current year.

The trial process was scheduled in the winter season (January-February) for a 42-day period (six weeks) and the objective was to determine the efficiency of the BIM based optimization for FIDIA over this interval in comparison with the previous year's consumption records from historical data (referred to as traditional optimization).

It must be noted that the optimization process was conducted based on real input data recorded from the pilot, to which we applied BIM optimization deployed on our computing infrastructure. For the experiments reported in this section, traditional optimization (no intelligence) refers to those existing pilot techniques that involve human intervention (i.e., manually changing a boiler setpoint) and using historical data from the previous year, whereas BIM-based optimization assumes an automated and intelligent building optimization and actuation. The BIM-based optimization is presented in Section 4 .

Experiment 1: Energy Consumption: BIM Optimization vs. Traditional Optimization

Figure 3 illustrates how energy consumption evolved in FIDIA over a monitored period of one day (24 h). It can be observed that the energy consumption, as recorded in the pilot and undertaken with traditional optimization methods, fluctuates between 0 and $100 \mathrm{~kW} \cdot \mathrm{h}$ with a peak value of $300 \mathrm{~kW} \cdot \mathrm{h}$. For the BIM optimization, the energy consumption fluctuated over the interval of $(0-38) \mathrm{kW} \cdot \mathrm{h}$. We can immediately conclude that BIM optimization imposes a uniformity over the energy consumption.

This experiment has been tested on the FIDIA pilot, on the 23rd of December and started at 08:01 a.m. To conduct this experiment, we applied the BIM optimization method presented in Section 4 (Figure 2), sensing occupancy, indoor and outdoor variables. We scheduled optimization periodically at 15 min intervals and implemented an optimized temperature airflow setpoint within the BMS system. 
The traditional optimization used historical data from the same day of the previous year. For the traditional optimization, we initially recorded consumption data from a sensor that only broadcasted rounded values. After technological upgrades, it was possible to record data with lower granularity and to present the BIM optimization results.

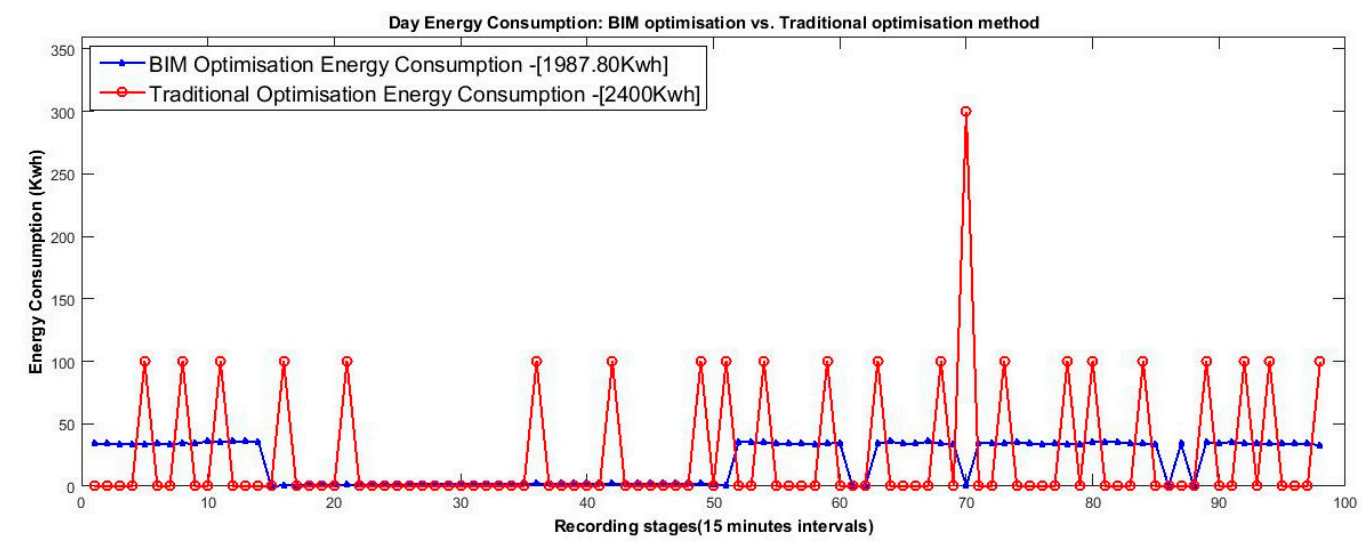

Figure 3. Day energy consumption.

From Figure 3, two consumption schedules can also be identified: (i) day schedule (0-20) recording stages and (50-96) stages and (ii) night schedules (20-50) recording stages. Whereas during the day schedule the energy consumption was high, over night the consumption was minimum. However, as traditional optimization techniques have no intelligent decision-making processes, for some night schedule intervals the energy consumption was still high. Our BIM-based optimization assumes a continuous adaptation based on the values read from the sensors. This process of continuous adaptation associated with an intelligent optimization mechanism facilitates significant energy savings. For the monitoring period of one day $(24 \mathrm{~h})$, the savings obtained by using BIM optimization were $412.20 \mathrm{~kW} \cdot \mathrm{h}$, equivalent with a saving percentage of approximately $39 \%$.

Experiment 2: Thermal Energy Consumption: BIM Optimization vs. Traditional Optimization

In this case, we were interested to show how thermal energy consumption (TEC) evolved within the two scenarios that we compared: (i) BIM optimization and (ii) traditional optimization. For a better comparison base, we used an additional artificial neuronal network (presented in Section 4.3) to predict energy consumption. The traditional optimization used historical data from the previous year of the same period (see Table 2).

Table 2. Thermal energy consumption dataset $(\mathrm{kW} \cdot \mathrm{h})$.

\begin{tabular}{cl}
\hline $\begin{array}{c}\text { Optimisation } \\
\text { Type }\end{array}$ & \multicolumn{1}{c}{ Optimisation Values } \\
\hline \multirow{2}{*}{ Traditional } & 60019002000170012001800180031002000180013002000200020002000210017001200 \\
& 18001200120015002000170012002300110011002000160020019002000190019001600 \\
\hline \multirow{3}{*}{ BIM } & 44001700180018001200 \\
& 41.4462 .39128 .4155 .1357 .3547 .5048 .5053 .5177 .0594 .3230 .45108 .45141 .4959 .2534 .4319 .89 \\
& 49.7354 .5158 .3244 .8575 .50105 .2153 .1040 .1757 .2044 .211 \\
\hline \multirow{2}{*}{ Predicted } & 499.551507 .931301 .0279 .33321 .09157 .4186 .08302 .47373 .64309 .18363 .19119 .42296 .08268 .14 \\
& 236.54328 .20169 .55304 .67128 .4392 .99153 .2348 .53391 .98152 .60204 .80176 .13108 .45141 .49 \\
& 168.22211 .8219 .89125 .86127 .22230 .23142 .05182 .47143 .94160 .90154 .31129 .48149 .90 \\
\hline
\end{tabular}

From Figure 4, it can be identified that our BIM optimization model facilitates significant energy savings. It is important to note that this experiment illustrates the total thermal energy consumption 
per day over the monitored interval of 42 days (six weeks), as part of a trial process scheduled in the winter season (January-February). As illustrated, the thermal energy consumption with traditional optimization was high, varying over the interval of (500-3100) $\mathrm{kW} \cdot \mathrm{h}$ with an average per day of $1665.85 \mathrm{~kW} \cdot \mathrm{h}$. On the other hand, the optimized thermal energy consumption evolved within the interval (50-1500) $\mathrm{kW} \cdot \mathrm{h}$, with an average per day of $257.77 \mathrm{~kW} \cdot \mathrm{h}$. The peaks identified on day \#8 and on day \#31 are associated with a change in outdoor temperature. On day \#8, a low temperature was recorded, therefore more energy was needed to heat the pilot, whereas on day \#31, the energy consumption requirement decreased due to an increase in the outdoor temperature.

This process of continuous adaptation associated with an intelligent BIM optimization mechanism facilitates significant energy savings as the BIM optimization reacts according to the latest changes within the building at 15 min intervals.

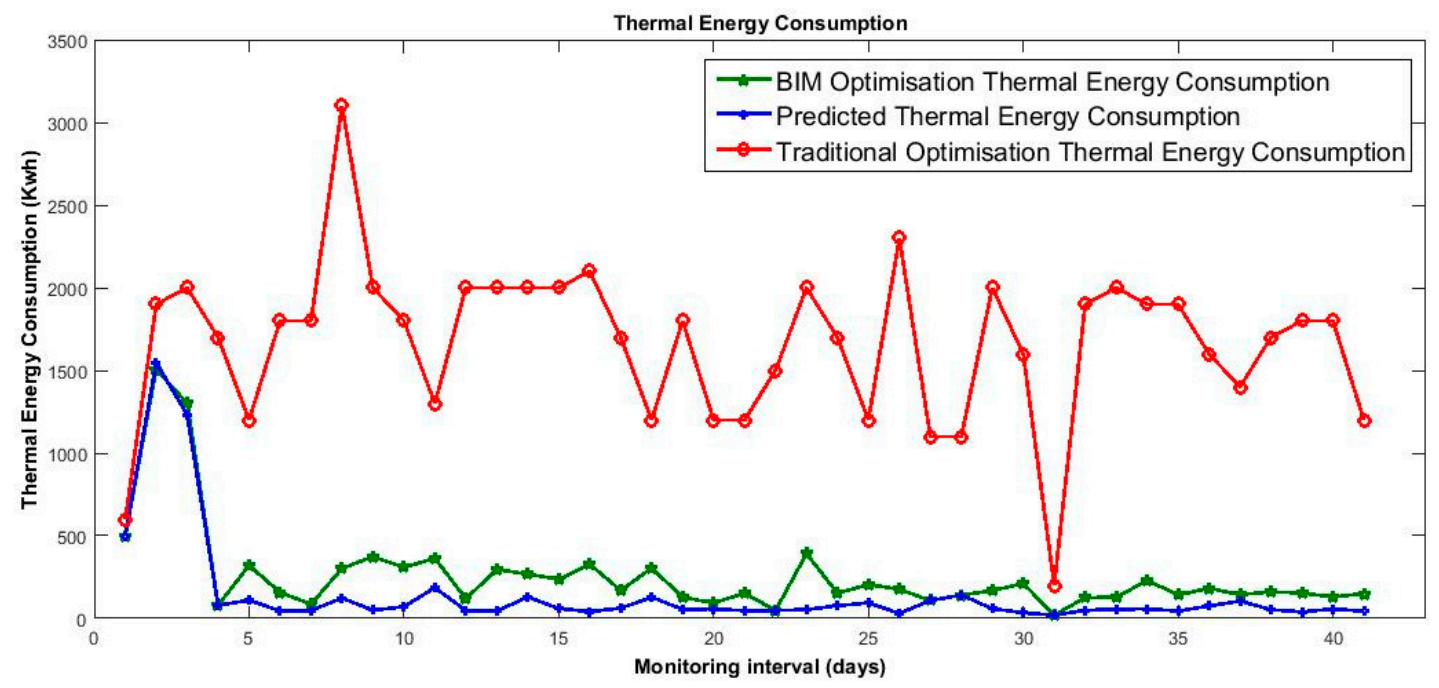

Figure 4. Total thermal energy consumption $(\mathrm{kW} \cdot \mathrm{h})$ : BIM optimization vs. traditional optimization method.

Experiment 3: Electrical Energy Consumption: BIM Optimization vs. Traditional Optimization

In this experiment, we were interested to show which was the impact of our BIM optimization system on the electrical energy consumption (EEC). It is important to note that in the FIDIA pilot the electrical energy consumption was at a minimum as it was only used to heat the air in the fans. The traditional optimization uses historical data from the previous year of the same period (see Table 3).

Table 3. Electrical energy consumption dataset $(\mathrm{kW} \cdot \mathrm{h})$.

\begin{tabular}{|c|c|}
\hline $\begin{array}{l}\text { Optimisation } \\
\text { Type }\end{array}$ & Optimisation Values \\
\hline Traditional & $\begin{array}{l}59209.80207 .80170 .60119 .40211 .20207327 .80211 .20172 .40123209209 .20207 .60204 .80 \\
211.80173 .40122204 .80181 .80183 .40180203164124 .20212 .40140 .80144 .80202 .40187 .60 \\
14.60207 .20209 .20208 .20212170 .80122 .60208 .40211 .20208 .60121 .20\end{array}$ \\
\hline BIM & $\begin{array}{l}1.805 .616 .324 .283 .175 .175 .027 .704 .563 .633 .244 .124 .225 .164 .294 .644 .483 .214 .623 .333 .36 \\
3.113 .874 .203 .144 .523 .163 .133 .432 .710 .504 .765 .074 .003 .714 .243 .133 .335 .154 .763 .29\end{array}$ \\
\hline Predicted & $\begin{array}{l}1.805 .566 .124 .223 .614 .984 .597 .144 .453 .973 .434 .394 .605 .024 .204 .574 .393 .544 .453 .733 .80 \\
3.124 .164 .353 .364 .643 .163 .133 .463 .000 .504 .494 .443 .864 .144 .343 .263 .604 .904 .322 .93\end{array}$ \\
\hline
\end{tabular}

Figure 5 shows how electrical energy consumption evolved in the two cases that we analysed. Whereas for the traditional optimization the consumption was high, fluctuating over the interval of (59-330) kW.h with an average of $180 \mathrm{~kW} \cdot \mathrm{h}$ per day, when using our BIM optimization system the consumption dropped to an average of $4.04 \mathrm{~kW} \cdot \mathrm{h}$ per day. Thus, we demonstrate again that 
BIM optimization undertaken with a frequency interval of $15 \mathrm{~min}$ can greatly contribute to reducing electrical energy consumption.

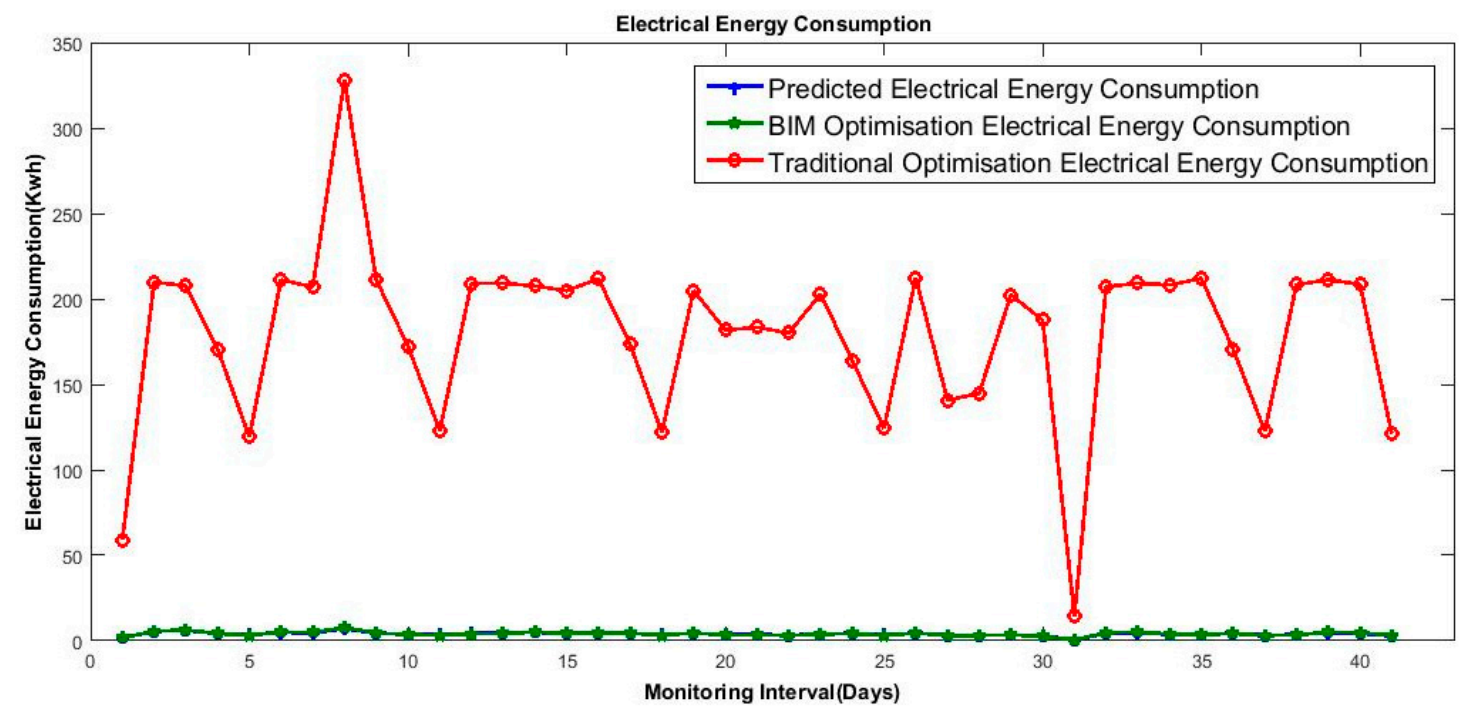

Figure 5. Total electrical energy consumption $(\mathrm{kW} \cdot \mathrm{h})$ : BIM optimization vs. traditional optimization method.

\section{Emphasizing the BIM Role in Energy Efficiency and Sector Challenges}

In our European societies, as well as in most parts of the world, education is recognized as a key pillar of community life and a universal right. The literature also puts a particular emphasis on the clear relationship between education and social stability, demonstrating that increasing access to postsecondary vocational education and training significantly reduces property crime, drug crime and crime against the person $[1,45,46]$.

Previous sections contributed to demonstrating the importance of digital technologies in the transformation of European businesses, and especially in the construction sector, which face huge environmental and economic challenges. Today, it is recognized that building information modelling is an essential way to improving the whole value chain in the construction sector, as stated in the last report of European Construction Technology Platform's energy efficient buildings committee [45]. In particular, the report recognizes "the capacity of BIM to integrate building information and create a collaborative environment makes it a powerful tool for developing simulations of a wide range of specialties, such as energy analysis" (p. 20). In relation to BIM, ongoing projects address significant research and industrial challenges related to data interoperability, optimization of building operations, as well as the management of building blocks and smart cities. Such a BIM-driven approach, however, faces a three-sided challenge in the construction industry:

- Construction is a key component of the energy union strategy [46], and as such faces huge pressure from the EU and national regulations. Buildings represent $40 \%$ of primary energy consumption in the EU and between $30 \%$ and $40 \%$ of $\mathrm{CO}_{2}$ emissions depending on national energy mixes. Improving the energy efficiency of European buildings is therefore a key step in achieving the 2020, 2030 and $2050 \mathrm{EU}$ energy and $\mathrm{CO}_{2}$ emission targets. European energy directives, in particular the energy-efficiency directive (EED), the energy performance of buildings directive (EPBD), and related national regulations, set very strict energy-efficiency targets for European buildings, with the aim to implement near-zero energy buildings (NZEB) by 2020. NZEB are highly complex systems, which call for significant technical progress in several areas, including building envelope performance, energy and comfort monitoring, and the integration of renewable energy production [1]. 
- The construction sector is still facing the consequences of the economic crisis, which has reduced the investment capacities of its companies. The European sector is a strong economic sector (10\% of the EU GDP) but it is also essentially made of small and very small companies, which have been particularly impacted by the economic downturn. This is one of the reasons why the financing of the required European building stock enhancement through deep renovation (up to 100 billion euros per year until 2020), is recognized as a challenge by the European Commission [47]. Cost-effectiveness and productivity are therefore two overarching issues for European construction businesses.

- The European construction industry is experiencing its digital revolution, with an intensification of digital support in all stages of building design and construction. The building information modelling (BIM) approaches and tools have in particular gained significant interest in the sector [48]. They are recognized as key components of future construction practices, and their benefits on productivity and reliability are widely acknowledged. This evolution contrasts with the original culture and practices of the construction sectors, which is widely perceived as a "low-tech" area with a significant proportion of "blue collar" workers. Training is therefore, even more than in other economic sectors, a critical challenge of our time.

To anchor this digital shift in a secure environment at the EU scale, the whole construction value chain has to increase its digital skills. Enhancing the BIM qualifications and skills of workers is therefore particularly critical. Training the construction workforce therefore becomes essential to addressing the digital shift, as well as the future expectations of owners regarding the efficiency and sustainability of operations (see Figure 6). Considering the whole value chain, it is clear that all the stakeholders have to be trained to increase their specific skills, from managers and engineers (owners, design teams), to construction managers and workers themselves ("blue collar"). Logically all the phases comprised in the building lifecycle have to be addressed, while considering the added-value of digital models (BIM/BEM) and associated electronic processes for exchanging information amongst project teams. Regarding this latter aspect, information delivery manuals (IDM, the processes enabling authoring and exchanging BIM models) are key and they should be extended and well-verified for purposes related to energy efficiency.

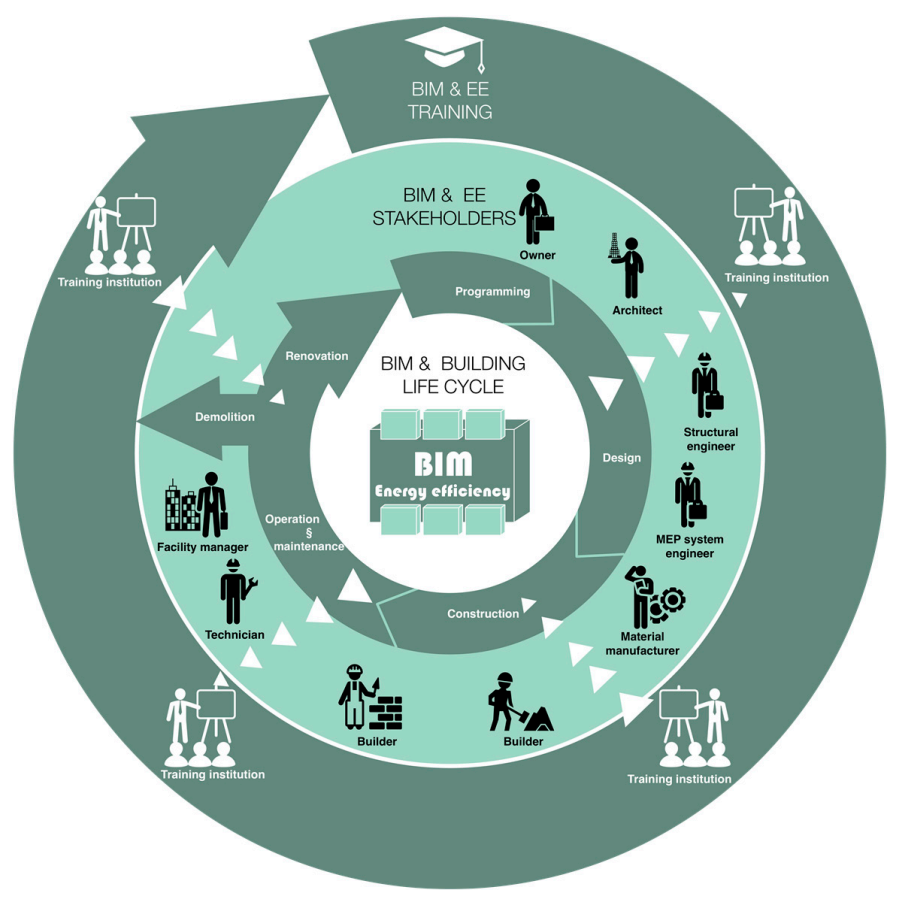

Figure 6. A holistic approach to BIM and energy efficiency training. 


\section{Conclusions}

The paper focuses on a particular case study highlighting the role of BIM in energy efficiency and to support the emissions reduction agenda. We identify possible applications of BIM in the building lifecycle while relying on literature review. Beyond, we highlight that only few research papers addressed so far applications of BIM in operation phase to enhance energy efficiency methods and systems. Thus, we provide a real application use case to demonstrate the impact of BIM at building operation phase focusing on energy efficiency. The proposed BIM optimization is grounded in a holistic and global approach to energy efficient building management. The experiments conducted prove the interest and added-value of the approach. However, some barriers can be identified.

This data-driven method requires not only accurate BIM and BEM models, but also the combined acquisition of a building's operation data through automated sensing of physical parameters as well as human-centric identification of perceived comfort levels. Beside the issues raised by the management of such heterogeneous digital datasets, one can recognize the need for inter-disciplinary thinking when implementing such a BIM optimization method on an actual building. Engineering knowledge and methods should be combined to human-science-based techniques to devise on data collection and interpretation in a clever approach for each building considered.

Although we focused on a specific case study, we consider there are several areas that are key to the potential growth of BIM for energy efficiency and its impact on the green building marketplace:

- Multi-disciplinary integrative capacity of BIM: BIM provides a unique opportunity to integrate data, information and underpinning processes across lifecycles and supply chains. This will promote informed and energy-efficient design interventions.

- Informed sustainability design: BIM contributes to sustainable lifecycle decisions and processes as it leverages the capability of the complete construction value chain, thus optimizing design decisions on complex issues such as energy efficiency.

- Modelling standards: BIM is currently promoting the development and adoption of a wide range of standards and best practice guides, as evidenced by BIM adoption dynamics in the UK.

- Increase of BIM use for retrofitting: there is an increasing trend for the use of BIM in large as well as smaller projects with a sought benefit of maximizing energy efficiency and sustainable outcomes. Recognition of the appropriateness of BIM for small retrofit projects is also critical given the dynamic growth anticipated in the green retrofit market in the existing domestic stock across Europe.

- Using BIM for building performance monitoring: there is increasing evidence of the value of BIM tools during the operations and maintenance phase of a project, with the view of reducing the endemic gap between predicated and actual energy consumption in buildings.

- Training support and communication tools: as BIM embraces building products and processes, it constitutes a useful support for training, and for communicating best practices for energy-efficient and high-quality construction, in particular to on-site staff.

The European construction industry (and beyond) is currently facing fragmentation and inadequate training resources. It is therefore necessary to raise the awareness of stakeholders in the construction value chain about (a) environmental challenges; (b) current and future sustainability scenarios; and (c) energy efficiency targets and European Commission (EC) and governments agendas, with a view to delivering informed built-environment interventions across lifecycles and supply chains underpinned by an effective BIM-based Europe-wide training agenda.

In this paper, we used BIM for the operation phase and emphasized the benefits that can be derived from such an approach regarding energy optimization and emission reductions. However, BIM for energy efficiency represents an on-going process requiring specialized training in order to develop skills and competencies for the entire construction community. Such training can provide several advantages across the entire construction industry: (a) pave the way to fundamental change 
in delivering systematic, measurable and effective energy-efficient buildings; and (b) promote a new generation of decision-makers, practitioners, and "blue collar" workers in BIM for energy efficiency.

Acknowledgments: The authors acknowledge financial support from the European Commission (H2020) to the BIMEET project, grant reference: 753994. Our validation use-case has been part of the EU FP7 SportE2 project grant number: 260124.

Author Contributions: Ioan Petri and Yacine Rezgui conceived and designed the experiments; Ioan Petri analysed the data; Ioan Petri and Haijiang Li performed the experiments; Yacine Rezgui, Haijiang Li, Sylvain Kubicki and Annie Guerriero advised with the BIM applicability scenario; Sylvain Kubicki and Annie Guerriero contributed with the methodology framework and analysis tools; Ioan Petri, Yacine Rezgui, and Sylvain Kubicki wrote the paper.

Conflicts of Interest: The authors declare no conflict of interest. The founding sponsors had no role in the design of the study; in the collection, analyses, or interpretation of data; in the writing of the manuscript, and in the decision to publish the results.

\section{References}

1. European Commission. Directive 2010/31/Eu of the European Parliament and of the Council of 19 May 2010 on the Energy Performance of Buildings. Official Journal of the European Union. Available online: http:/ / eur-lex.europa.eu/LexUriServ/LexUriServ.do?uri=OJ:L:2010:153:0013:0035:en:PDF (accessed on 2 August 2017).

2. Challenging and Changing Europe's Built Environment: A Vision for a Sustainable and Competitive Construction Sector by 2030. Report from European Construction Technology Platform. 2005. Available online: https: / / www.certh.gr/dat/79DC02A3 / file.pdf (accessed on 2 August 2017).

3. Perspectives, Global Construction, and Oxford Economics. Global Construction 2030: A Global Forecast for the Construction Industry to 2030; Global Construction Perspectives and Oxford Economics: London, UK, 2015.

4. IHS Economics. Global Construction Outlook: Executive Outlook; IHS Economics: London, UK, 2013.

5. Rezgui, Y.; Miles, J.C. Harvesting and Managing Knowledge in Construction: From Theoretical Foundations to Business Applications; Taylor \& Francis Group Ltd: Oxford, UK, 2011; ISBN 9780415545952.

6. Petri, I.; Beach, T.; Rezgui, Y.; Wilson, I.E.; Li, H. Engaging construction stakeholders with sustainability through a knowledge harvesting platform. Comput. Ind. 2014, 65, 449-469. [CrossRef]

7. Boton, C.; Kubicki, S.; Halin, G. Designing adapted visualization for collaborative 4D applications. Autom. Constr. 2013, 36, 152-167. [CrossRef]

8. Yuce, B.; Rezgui, Y. An ANN-GA Semantic Rule-Based System to Reduce the Gap between Predicted and Actual Energy Consumption in Public Buildings. IEEE Trans. Autom. Sci. Eng. 2015, 14, 1351-1363. [CrossRef]

9. Petri, I.; Li, H.; Rezgui, Y.; Chunfeng, Y.; Baris, Y.; Jayan, B. A modular optimization model for reducing energy consumption in large scale building facilities. Renew. Sustain. Energy Rev. 2014, 38, 990-1002. [CrossRef]

10. Barrett, P.; Sexton, M. Innovation in Small, Project-Based Construction Firms. Br. J. Manag. 2006, 17, 331-346. [CrossRef]

11. Bryde, D.; Broquetas, M.; Volm, I.M. The project benefits of Building Information Modelling (BIM). Int. J. Proj. Manag. 2013, 31, 971-980. [CrossRef]

12. Latham, M. Constructing the Team: Final Report of the Government/Indus try Review of Procurement and Contractual Arrangements in the UK Construction Industry; Stationery Office Books: London, UK, 1994.

13. Egan, J. Rethinking Construction; Department of the Environment, Transport and Regions: London, UK, 1998.

14. Dainty, A.; Moore, D.; Murray, M. Communication in Construction: Theory and Practice; Taylor \& Francis: Oxford, NY, USA, 2006.

15. Becerik-Gerber, B.; Jazizadeh, F.; Li, N.; Calis, G. Application areas and data requirements for BIM-enabled facilities management. J. Constr. Eng. Manag. 2011, 138, 431-442. [CrossRef]

16. Cerovsek, T. A review and outlook for a 'Building Information Model' (BIM): A multi-standpoint framework for technological development. Adv. Eng. Inform. 2011, 25, 224-244. [CrossRef]

17. Standardized Vocational Education and Training for BIM in EU (BIM4VET). European Research Project. Available online: http:/ / www.bim4vet.eu (accessed on 2 August 2017).

18. Wilkins, C.; Kiviniemi, A. Engineering-centric BIM. ASHRAE J. 2008, 50, 44-48. 
19. Ladenhauf, D.; Battisti, K.; Berndt, R.; Eggeling, E.; Fellner, D.W.; Gratzl-Michlmair, M.; Ullrich, T. Computational geometry in the context of building information modeling. Energy Build. 2016, 115, 78-84. [CrossRef]

20. Schlueter, A.; Thesseling, F. Building information model based energy/exergy performance assessment in early design stages. Autom. Constr. 2009, 18, 153-163. [CrossRef]

21. Azhar, S.; Carlton, W.A.; Olsen, D.; Ahmad, I. Building information modeling for sustainable design and LEED rating analysis. Autom. Constr. 2011, 20, 217-224. [CrossRef]

22. Cemesova, A.; Hopfe, C.J.; Rezgui, Y. An approach to facilitating data exchange between BIM environments and a low energy design tool. In Proceedings of the BS2013, 13th Conference of International Building Performance Simulation Association, Chambery, France, 25-30 August 2013.

23. Howell, S.; Rezgui, Y.; Hippolyte, J.-L.; Jayan, B.; Li, H. Towards the next generation of smart grids: Semantic and holonic multi-agent management of distributed energy resources. Renew. Sustain. Energy Rev. 2017, 77, 193-214. [CrossRef]

24. Costa, A.; Keane, M.M.; Torrens, J.I.; Corry, E. Building operation and energy performance: Monitoring, analysis and optimisation toolkit. Appl. Energy 2013, 101, 310-316. [CrossRef]

25. Wong, J.K.W.; Zhou, J. Enhancing environmental sustainability over building life cycles through green BIM: A review. Autom. Constr. 2015, 57, 156-165. [CrossRef]

26. Ufuk Gökçe, H.; Umut Gökçe, K. Integrated System Platform for Energy Efficient Building Operations. J. Comput. Civ. Eng. 2014, 28, 05014005. [CrossRef]

27. Reeves, T.; Olbina, S.; Issa, R.R. Guidelines for using Building Information Modeling for energy analysis of buildings. Buildings 2015, 5, 1361-1388. [CrossRef]

28. Portable, Exhaustive, Reliable, Flexible and Optimized Approach to Monitoring and Evaluation of Building Energy Performance (PERFORMER), EU FP7. Available online: http:/ / performer-project.eu (accessed on 4 August 2017).

29. Knowledge-Based Energy Management for Public Buildings through Holistic Information Modeling and 3D Visualization (KnoholEM), EUFP7. Available online: http:/ / www.knoholem.eu (accessed on 2 August 2017).

30. Sebastian, R.; Böhms, H.M.; Bonsma, P.; van den Helma, P.W. Semantic BIM and GIS modelling for energy-efficient buildings integrated in a healthcare district. In Proceedings of the ISPRS 8th 3DGeoInfo Conference \& WG II/2 Workshop, Istanbul, Turkey, 27-29 November 2013; Volume II-2.

31. Lobaccaro, G.; Carlucci, S.; Löfström, E. A review of systems and technologies for smart homes and smart grids. Energies 2016, 9, 348. [CrossRef]

32. European Sustainable Urban Consolidation CentrES for conStruction (SUCCESS), EU H2020. Available online: http:/ / www.success-urbanlogistics.eu/ (accessed on 31 January 2017).

33. Delponte, E.; Ferrando, C.; Di Franco, M.; Hakkinen, T.; Rekola, M.; Abdalla, G.; Casaldàliga, P.; Pujols Ortiz, C.; Lopez Vega, A.; Shih, S.-G. Holistic and optimized life-cycle integrated support for energy-efficient building design and construction: HOLISTEEC methodology. In eWork and eBusiness in Architecture, Engineering and Construction, Proceedings of the 10th European Conference on Product and Process Modelling (ECPPM), Vienna, Austria, 17-19 September 2014; CRC Press: Boca Raton, FL, USA, 2014.

34. Affirmative Integrated Energy Design Action, AIDA, EU FP7. Available online: http:/ / www.aidaproject.eu (accessed on 31 January 2017).

35. Review of the EPBD, Including the Smart Financing for Smart Building Initiative, DG ENER, UNIT C3-2016/ENER/001. November 2015. Available online: http:/ / ec.europa.eu/smart-regulation/roadmaps/ docs/2016_ener_001_epbd_smart_buildings_en.pdf (accessed on 20 September 2016).

36. BIM 2016 in the UK. Available online: http:/ / www.bimtaskgroup.org/ (accessed on 2 August 2017).

37. Mott-MacDonald. Building Performance Engineering. The Art of Science of Creating Great Outcomes. Available online: https://www.mottmac.com/download/file/127/23554/building-performanceengineeringpdf (accessed on 2 August 2017).

38. BPIE. Available online: http://www.bpie.eu/uploads/lib/document/attachment/21/LR_EU_B_under_ microscope_study.pdf (accessed on 12 September 2014).

39. A Framework Strategy for a Resilient Energy Union with a Forward-Looking Climate Change Policy, Communication from the Commission. February 2015. Available online: http:/ / eur-lex.europa.eu/legalcontent/EN/TXT/?uri=COM:2015:80:FIN (accessed on 2 August 2017). 
40. Crawley, D.B.; Lawrie, L.K.; Winkelmann, F.C.; Buhl, W.; Huang, Y.; Pedersen, C.O.; Strand, R.K.; Liesen, R.J.; Fisher, D.E.; Witte, M.J.; et al. Energyplus: Creating a new-generation building energy simulation program. Energy Build. 2001, 33, 319-331. [CrossRef]

41. Deb, K.; Pratap, A.; Agarwal, S.; Meyarivan, T. A fast and elitist multiobjective genetic algorithm: NSGA-II. IEEE Trans. Evolut. Comput. 2002, 6, 182-197. [CrossRef]

42. Atthajariyakul, S.; Leephakpreeda, T. Neural computing thermal comfort index for HVAC systems. Energy Convers. Manag. 2005, 46, 2553-2565. [CrossRef]

43. EnergyPlus. Available online: https:// energyplus.net/ (accessed on 31 January 2017).

44. Simergy. Available online: http://energy-models.com/software/simergy (accessed on 31 January 2017).

45. International Covenant on Economic, Social and Cultural Rights; Article 13.1; United Nations Headquarters: New York, NY, USA, 1966.

46. European Commission. 2015. Available online: http://ec.europa.eu/energy/en/topics/energy-efficiency/ energy-efficiency-directive (accessed on 2 August 2017).

47. Measuring the Impact of BIM on Complex Buildings; SmartMarket Report; Dodge Data \& Analytics: Arlington, TX, USA, 2015.

48. European Construction Technolgy Platform. EeB PPP Project Review 2016. March 2016. Available online: http:/ / ectp.org/fileadmin/user_upload/documents/E2B/EeB_PPP_Project_Review_2016.pdf (accessed on 10 March 2017).

(C) 2017 by the authors. Licensee MDPI, Basel, Switzerland. This article is an open access article distributed under the terms and conditions of the Creative Commons Attribution (CC BY) license (http:/ / creativecommons.org/licenses/by/4.0/). 